\title{
Time Trends and Geographic Variations for Thyroid Cancer in New Caledonia, a Very High Incidence Area (1985-1999)
}

\author{
Thérèse Truong ${ }^{1}$ \\ Yannick Rougier ${ }^{2}$ \\ Dominique Dubourdieu ${ }^{3}$ \\ Chantal Guihenneuc-Jouyaux ${ }^{1,4}$ \\ Laurent Orsi ${ }^{1}$ \\ Denis Hémon ${ }^{1}$ \\ Pascal Guénel ${ }^{1}$
}

\section{Author's affiliations}

1 INSERM, U754, IFR69, Université Paris-Sud, F-94807 Villejuif, France

2 Institut Pasteur de Nouvelle-Calédonie, Nouméa, New Caledonia

3 Laboratoire d'Anatomie et de Cytopathologie, Nouméa, New Caledonia

4 CNRS UMR 8145, Université Paris 5, F-75006 Paris, France

\section{Author for correspondence}

Pascal Guénel, MD, PhD

INSERM U754

16 avenue Paul Vaillant-Couturier

94807 Villejuif Cedex

France

mail: guenel@vif.inserm.fr

Running head: Incidence of thyroid cancer in New Caledonia 


\section{ABSTRACT}

Objective: Thyroid cancer incidence in New Caledonia is the highest reported in the world and is approximately 10 -fold higher than in most developed countries. We describe the incidence patterns in this country according to histological and sociodemographic characteristics to give clues about potential etiologic factors. Another objective is to see whether the incidence figures are related to enhanced detection of small size carcinomas.

Methods: The study included all 498 cases of thyroid cancer diagnosed in 1985-1999. Pathology reports were systematically reviewed to determine the histological type of the tumor and the size of the cancerous nodules. The incidence of carcinomas $\leq 10 \mathrm{~mm}$ was taken as an indicator of enhanced detection due to improved screening procedures.

Results: The age-standardized incidence rates in 1985-1999 were exceptionally high in Melanesian women $(71.4 / 100,000)$ and men $(10.4 / 100,000)$. The incidence increased three-fold in women from 1995 onwards. The increase in incidence was more striking for papillary carcinomas $\leq 10 \mathrm{~mm}$ than for large size carcinomas, but an increased incidence of carcinomas $>10 \mathrm{~mm}$ was also observed among women. The analysis by municipality of residence in Melanesian women showed that the incidence was twice as high in 1995-1999 in the Loyalty Islands as in the rest of the country.

Conclusion: The sharp increase of thyroid cancer incidence in 1985-1999 in New Caledonia was partly related to enhanced detection of small size carcinomas. The elevated incidence of thyroid cancers, as well as the ethnic and geographic disparities, may result from common environmental or lifestyle risk factors that need to be identified.

\section{Keywords}

Incidence; New Caledonia; thyroid neoplasms 


\section{INTRODUCTION}

Thyroid cancer accounts for approximately $1 \%$ of total cancer cases, but it is the most frequent endocrine malignancy (Stewart and Kleihues, 2003). The incidence of thyroid cancer ranges from approximately 3 to 8 per 100,000 women and 1 to 4 per 100,000 in men in developed countries, but there is considerable geographic variation in thyroid cancer incidence around the world (Ferlay et al., 2004). Elevated incidence was reported in Iceland (Hrafnkelsson et al., 1988), Central Italy (Franceschi et al., 1998) and in some Pacific populations (Paksoy, 1988). Ethnic differences in incidence has also been noted in Hawaii with higher rates among Filipinos than in other ethnic groups (Goodman et al., 1988). In United States, Black men and women had significantly lower rates than Whites (Spitz et al., 1988). In addition to geographic and ethnic variations of thyroid cancer incidence, marked increases of thyroid cancer incidence, essentially papillary carcinomas, were observed in North America (Zheng et al., 1996; Liu et al., 2001; Hodgson et al., 2004), Europe (Akslen et al., 1993; dos Santos Silva and Swerdlow, 1993; Colonna et al., 2002; Verkooijen et al., 2003; Mahoney et al., 2004; Reynolds et al., 2005) and Australia (Burgess, 2002). It has been suggested in recent reports that improved screening of thyroid cancer is the main explanation for these time trends (Colonna et al., 2002; Leenhardt et al., 2004a,b; Reynolds et al., 2005; Verkooijen et al., 2003; Hodgson et al., 2004). However, the causes for the variations in thyroid cancer incidence are still not known.

The incidence of thyroid cancer in New Caledonia, a French territory in South Pacific, is remarkably elevated. In a previous study conducted by Ballivet et al. (1995), the incidence rate reported in 1985-1992 for Melanesian women was 34.9 per 100,000, the highest incidence figure ever reported. No clear explanation is currently available for this elevated incidence, although we have shown that it may be partly accounted for a high parity and other reproductive factors that are common in Melanesian women of New Caledonia (Truong et al., 2005). In order to provide clues on potential etiologic factors of thyroid cancer, the incidence was examined in this paper over an extended study period (1985-1999). This analysis permitted to study time trends and geographic variations within the country. Because high incidence of thyroid cancer due to improved screening is generally associated with an elevated proportion of small 
carcinomas (Verkooijen et al., 2003), data on tumor size were obtained for the present study as an indicator of enhanced diagnostic procedures for thyroid cancer.

\section{SUBJECTS AND METHODS}

\section{Thyroid cancer cases}

All thyroid cancers diagnosed in 1985-1999 were identified from the two pathology laboratories, one public and one private, operating in New Caledonia. In order to achieve a complete registration, cases were also sought in the New Caledonia cancer registry that included thyroid cancer cases identified from the medical facilities, health insurance files and sanitary evacuation office (Ballivet et al., 2000). The identification of the thyroid cancer cases diagnosed in 1985-1992 was made retrospectively, and the data for this period have been published separately (Ballivet et al., 1995). In 1993-1999, all cases of thyroid cancer were recorded prospectively by the two pathology laboratories, and no additional thyroid cancer patient diagnosed in this period was found after cross-checking with the cancer registry. No case of thyroid cancer was identified at autopsy.

Thyroid carcinomas were coded from the original pathology report according to International Classification of Diseases for Oncology (1990) in four histological groups (papillary, follicular, anaplastic and medullary). Mixed papillary/follicular carcinomas were classified as papillary carcinomas as recommended by the WHO (Hedinger et al., 1988). For the cases diagnosed in 1993-1999, the pathology reports were used to determine the number and the size of the cancerous nodules. When this information was missing, it was obtained from the pathologist by reviewing the original histological slides. The diameter of the largest cancerous nodule permitted to classify thyroid cancers as microcarcinomas $(\leq 10 \mathrm{~mm})$ or carcinomas $>10$ $\mathrm{mm}$. Unfortunately, the size of the carcinomas for cases before 1993 could not be obtained because this information was not systematically recorded on the original pathology report, and because the histological slides were not readily available for review. All thyroid cancer cases were also characterized by gender, date of birth, date of diagnosis, ethnic group (European, Melanesian, Polynesian, Asian, other) and municipality of residence at diagnosis. 
Population

New Caledonia is composed of the North and South Provinces constituting the mainland, and of the Province of Loyalty Islands. The country is further divided in 32 municipalities. The population is concentrated in the South $(135,000$ inhabitants in 1996, including Nouméa the main city). The North $(41,000)$ and the Loyalty Islands $(21,000)$ are less populated (ITSEE-INSEE, 1997). In 1996, the population consisted in 44\% Melanesians, 34\% Europeans and $22 \%$ of other ethnic groups. Melanesians represented $25 \%, 78 \%$ and $97 \%$ of the population in the South, North and Loyalty Islands, respectively (ITSEE-INSEE, 1997).

Population figures during the study period (1985-1999) were estimated using the population censuses conducted in 1989 and in 1996. The Statistics Institute of New Caledonia provided cross-tabulations by sex, year of birth, ethnic group and municipality of residence for each census. Annual population estimates for each birth cohort tabulated by gender, ethnic group and municipality were obtained for the years 1990 through 1995 by diagonal linear interpolation between censuses (Pottier, 1992). Annual figures for the years before 1989 (19851988) and after 1996 (1997-1999) were estimated by linear extrapolation of the population trends. Person-years were calculated from these estimates by grouping the population figures by gender, age groups and calendar periods.

\section{Statistical analysis}

Age-standardized incidence rates per 100,000 person-years (ASR) were calculated using direct standardization to the world standard population by five-year age groups.

Time trends were studied using average annual percent changes (AAPC) derived from a Poisson regression model with adjustment on age (Breslow and Day, 1987). To examine the period and cohort effects, incidence rates by age group were plotted in two graphs with the period of diagnosis or the birth cohort as horizontal coordinates. This simple classical approach (Robertson and Boyle, 1998) was preferred to statistical modeling of the age, period and cohort effects because the study period was too short and the number of cases was too small to adjust formally a reliable age-period-cohort model.

Age-standardized incidence ratios (SIR) by municipality of residence were calculated for Melanesian women separately in 1985-1994 and in 1995-1999, using the incidence of thyroid cancer for all Melanesian women in New Caledonia in the corresponding calendar period as a 
standard. The ratio of the SIR in 1995-1999 to the SIR in 1985-1994 was also calculated for each municipality to measure the change of thyroid cancer incidence between the two periods, using the incidence in 1985-1999 as a standard for calculating the SIRs. Because of the small number of cases in certain areas, SIRs and SIR-ratios were estimated using the Besag, York and Mollié (BYM) Bayesian smoothing model (Besag et al., 1991), which takes into account the extra-Poisson variation and a geographical correlation between adjacent areas (Wakefield et al., 2000). A geographic gradient on the mainland was analyzed by including the geographic coordinates of the municipalities as a continuous variable in the regression model. Analyses were carried out using WinBUGS (Spielgelhalter et al., 2001). SIRs were mapped after sorting all municipalities in descending order of the SIRs and by determining four groups of municipalities, so that each group included approximately 25\% of the population in 1992 (median year of the study period).

\section{RESULTS}

A total of 498 thyroid cancers were diagnosed from 1985 to 1999 in 59 men and 439 women. Carcinomas were of the papillary type in 405 cases (81.3\%), follicular in 77 (15.5\%), anaplastic in $14(2.8 \%)$, medullary in one $(0.2 \%)$, and unspecified in one $(0.2 \%)$.

Time trends in 1985-1999

Age-standardized incidence rates by year of diagnosis are shown in figure 1. Among women, thyroid cancer incidence increased progressively from 1985 to 1994, rose sharply in 1995, and increased slightly again until 1998. Among men, the incidence increased slightly over the entire study period, but there was no abrupt increase in 1995 as it was observed in women. The average annual percent change of the thyroid cancer incidence in 1985-1999 was $13.5 \%$ (95\% confidence interval: $10.5,16.5)$ in women and $0.4 \%$ (95\% confidence interval: $-2.9,3.9)$ in men.

ASRs by gender, age group, ethnicity, province of residence and histology were studied separately for the calendar period before (1985-1994) and after (1995-1999) the sharp increase in incidence (table 1). Thyroid cancer incidence increased three-fold in women and two-fold in men from the first to the second period. It was higher in 1995-1999 than in 1985-1994 in all age groups, all ethnic groups and in the three Provinces. For the most part, the increase was due to 
papillary carcinomas. When examining each calendar period separately, it can be seen that thyroid cancer incidence was three to five times higher in Melanesians than in other ethnic groups, for both men and women. The incidence was particularly elevated in the Loyalty Islands, intermediate in the North, and lowest in the South. Although this difference reflected in part the ethnic composition of the Provinces, a similar gradient between geographic areas was observed when the incidence was examined in Melanesian women only.

Figure $2 \mathrm{a}$ and $2 \mathrm{~b}$ show incidence rates for women in 10-year age groups by calendar period of diagnosis and by birth cohort, respectively. In figure $2 \mathrm{a}$, the incidence of thyroid cancer was stable from 1985 to 1994 in all age group, with the exception of women 45-54 years old at diagnosis, and increased markedly in 1995-1999. The rise in incidence occurs simultaneously in all age groups, suggesting a period effect. In figure $2 \mathrm{~b}$, the curves representing the incidence by age group bend upward in different birth cohorts, e.g. for the 1920-1934 cohort in women aged 65-74 years and for the 1960-1974 cohort in women aged 25-34 years at diagnosis. This pattern is not indicative of a cohort effect, although the age groups in figure $2 b$ do not overlap sufficiently to formally exclude such an effect. In conclusion our data mostly support the existence of a period effect. This pattern may suggest the influence of some external factor that affected women in all age groups during the last five-year calendar period, such as changes in medical practices leading to improved diagnosis.

Time trends for papillary microcarcinomas in 1993-1999

Time trends in 1993-1999 were studied separately for papillary carcinomas $\leq 10 \mathrm{~mm}$ and for papillary carcinomas $>10 \mathrm{~mm}$ (table 2). Because the number of cases was small, years of diagnosis were grouped in three calendar periods as shown in the table. In Melanesian women, the incidence of microcarcinomas rose steadily from 11.6 , to 45.2 and to 71.0 per 100,000 in 1993-1994, 1995-1997, and 1998-1999, respectively (AAPC $=27.6 \%, 95 \%$ confidence interval: $14.4,42.2)$. The corresponding proportions of microcarcinomas were $28 \%, 46 \%$ and $63 \%$. In other ethnic groups, microcarcinomas increased noticeably in 1995-1997, but a further increase in the later calendar period was not apparent. The incidence of carcinomas $>10 \mathrm{~mm}$ also increased markedly in all ethnic groups, but none of the trends was statistically significant. 
Time trends by province were examined for Melanesian women only (table 3 ). The rates for microcarcinoma increased steadily over the study period in the Northern Province and in the Loyalty Islands, but it was stable in the Southern province in 1995-1997 and 1998-1999.

Geographic variations

Geographic variations are reported for Melanesian women only, because the number of cases was too small in other groups for meaningful analyses. Smoothed SIR of thyroid cancer by municipality are mapped for the periods 1985-1994 and 1995-1999 in figures 3a and 3b, respectively.

In 1985-1994 (figure 3a), the areas in the upper SIR category included the northernmost part of the mainland and Lifou, the largest Loyalty Island, with SIRs ranging from 1.05 to 2.79 . These municipalities contrasted sharply with the rest of the country where the SIR values were below or equal to 1.0. A statistically significant gradient of incidence was observed along the main axis (from south-east to north-west) of the mainland $(p<0.05)$.

In 1995-1999, geographic variations were quite different (figure 3b). SIRs for all the Loyalty Island (Ouvéa, Lifou, Maré) were in the upper quartile (0.85 to 2.04), whereas all SIRs for the mainland municipalities were in the three lower quartiles. On the mainland, the SIRs were somewhat higher in the southern than in the northern municipalities, but no statistically significant gradient was observed.

The ratio of the SIR in 1995-1999 to the SIR in 1985-1994 was above unity in all municipalities (map not shown), indicating that thyroid cancer incidence increased everywhere, with the exception of Pouébo where the incidence was stable (SIR-ratio=0.97). Interestingly, the increase in incidence was more striking in the south-east municipalities of the mainland and in the Loyalty Island Maré, i.e., in the municipalities where the incidence was the lowest in 19851994.

\section{DISCUSSION}

The incidence figures for thyroid cancer in Melanesian men and women of New Caledonia are the highest ever reported. An elevated incidence pattern in 1985-1992 has been described by Ballivet et al. (1995). This pattern was not only confirmed over an extended study 
period in the present paper, but the dramatic increase in incidence starting in 1995 makes the incidence of thyroid cancer in New Caledonia exceptionally high. Although papillary microcarcinomas account for part of the increase in incidence, thyroid carcinomas larger than $10 \mathrm{~mm}$ also had a remarkably elevated incidence, which also increased during the study period. There were important geographic variations of thyroid cancer incidence in Melanesian women across the country and clearly different patterns for the periods before and after 1995. Possible explanations for these observations are discussed below.

This study has several strengths including an exhaustive registration of thyroid cancer cases, a careful review of all pathology reports and histological slides that permitted to classify the cases according to homogeneous histological criteria, and according to cancer size for the carcinomas diagnosed in 1993-1999. The carcinoma size has rarely been reported in thyroid cancer incidence studies (Hodgson et al., 2004; Verkooijen et al., 2003). This information is important to consider, however, for a correct interpretation of the incidence trends, since the size of thyroid carcinomas diagnosed in a given period may be inversely related to cancer screening and enhanced surveillance of thyroid diseases (Leenhardt et al., 2004b). In the present paper we used the usual definition of microcarcinomas, i.e. carcinomas $\leq 10 \mathrm{~mm}$, in order to study the time trends. Sensitivity analyses were carried out using other cut-off points for the size of the carcinomas, but the conclusions were similar.

Demographic factors

Striking differences in thyroid cancer incidence between ethnic groups were observed, with rates several fold higher in Melanesians men and women than in other ethnic groups. Incidence rates in Melanesians women were as high as 120 per 100,000 in 1995-1999, making thyroid cancer the most frequent type of cancer in this group (Baumann and Rougier, 2005). Moreover, thyroid cancer incidence was about three times higher in European men and women living in New Caledonia, than men $(1.9 / 100,000)$ and women $(7.1 / 100,000)$ in France during the same period (Colonna et al., 2002). 
Time trends

The incidence of thyroid cancer, mostly papillary carcinomas, has been increasing since several decades in most industrialized countries in the world (Akslen et al., 1993; Colonna et al., 2002; dos Santos Silva and Swerdlow, 1993; Liu et al., 2001; Reynolds et al., 2005; Zheng et al., 1996; Hodgson et al., 2004; Verkooijen et al., 2003; Mahoney et al., 2004). Radioactive fallout following the Chernobyl accident is responsible for a dramatic rise of thyroid cancers in children living in heavily contaminated areas (Mahoney et al., 2004), but the causes of the increase of thyroid cancer in other parts of the world are still debated. Zheng et al. (1996) reported a birth cohort effect in the State of Connecticut and suggested that radiation treatment of benign childhood conditions between 1920 and 1950 was responsible for the observed increase in cohorts born between 1910 and 1945. In another study conducted in a previous endemic goiter area in Austria (Bacher-Stier et al., 1997), iodine supplementation in salt was associated with an increase of thyroid papillary cancers. In New Caledonia, it seems unlikely that radiation exposure or iodine supplementation can explain the increase of thyroid cancer. It should be pointed out that, in contrast to French Polynesia, no nuclear experiment was conducted in this area.

Recent studies have pointed out that the rise of papillary thyroid cancer incidence is mainly attributable to changes in histological criteria and in diagnostic procedures (Colonna et al., 2002; Hodgson et al., 2004; Leenhardt et al., 2004a,b; Reynolds et al., 2005; Verkooijen et al., 2003). Changes in histological criteria cannot explain the increase of thyroid carcinomas in New Caledonia since the same criteria were used to classify thyroid carcinomas over the entire study period. Most part of the increase in incidence observed in our data is likely related to important changes in diagnostic procedures such as the introduction of ultrasonography (Marqusee et al., 2000) or fine needle aspiration biopsy (Gharib and Goellner, 1993), as well as a more frequent use of total thyroidectomies (Leenhardt et al., 2004b). These procedures first introduced in metropolitan France in the 1980's (Leenhardt et al., 2004a), were widely applied in New Caledonia in the 1990's. This explanation is consistent with the sharp increase in incidence of microcarcinomas in 1995. It is also coherent with the increase in incidence observed in 19951999 (figure 2a) suggestive of a period effect. 
In Melanesian women, the incidence of papillary microcarcinomas increased 7-fold from 1993-1994 to 1998-1999. This increase can be accounted for the increase in thyroid cancer over the study period. However, it should be stressed that the incidence of thyroid cancer remained extremely elevated when only carcinomas $>10$ mm were considered. In 1993-1999, the incidence of thyroid carcinomas $>10 \mathrm{~mm}$ was $41.7 / 100,000$ in Melanesian women, i.e., several order of magnitude higher than the incidence of all papillary carcinomas in France among women at the same period $(5.8 / 100,000)$ (Colonna et al., 2002) where the diagnostic procedures for detecting thyroid cancers were similar.

\section{Geographic patterns}

For the study of the geographic variations, we estimated SIRs by municipality using a spatial smoothing model to avoid the high sampling variability in areas with small number of cases. In 1985-1994, the incidence was approximately twice as high in the northernmost part of the mainland and in the island of Lifou as in the rest of the country. In 1995-1999, a striking contrast was observed between all the Loyalty Islands and the mainland where the incidence was lower. From the first to the second calendar period, thyroid cancer increased in all the municipalities. The increase was small in the northernmost part of New Caledonia, where thyroid cancer incidence was the highest in 1985-1994. It was more pronounced in the South Province, where thyroid cancer incidence was the lowest in 1985-1994. Overall, this pattern suggests that the new diagnostic procedures were introduced earlier in the North than in the South. The elevated incidence in the Loyalty Islands in 1995-1999, as compared to the mainland, however, may be of particular interest for identifying clues on thyroid cancer etiology. The same geographic contrast persisted when only carcinomas $>10 \mathrm{~mm}$ diagnosed in 19951999 were considered (map not shown). Thus it can be hypothesized that the elevated incidence in the Loyalty Islands reflects the effect of as yet unidentified risk factors. Unlike the mainland of New Caledonia, the Loyalty Islands are coral islands, with soil and watershed composition that possibly determine antithyroid and goitrogenic effect of the drinking water (Gaitan, 1990), that in turn may be associated with a high thyroid cancer incidence. This and other hypotheses will be examined in an on-going analytical epidemiological study. 
Conclusion

The exceptionally high incidence of thyroid cancer in New Caledonia was partly related to enhanced screening of thyroid cancers, leading to increased incidence of thyroid microcarcinomas. However, when only carcinomas $>10 \mathrm{~mm}$ were considered, the incidence of thyroid cancer remained remarkably elevated, particularly among Melanesian women, indicating that specific risk factors for thyroid cancer are present in this group.

Although thyroid cancer is a major public health problem in New Caledonia, the factors explaining the elevated incidence are still unknown. The present study was helpful to provide clues on possible environmental or other factors. A case-control study in New Caledonia is currently in progress and will provide new information on the causes of thyroid cancer. 


\section{Acknowledgements}

This study was supported by grants from the "Fondation de France", the "Association pour la Recherche contre le Cancer", and the "Agence Française de Sécurité Sanitaire Environnementale (AFSSE)". The authors wish to thank Dr Francine Baumann (Cancer registry of New Caledonia), Dr Jean-Paul Grangeon (Direction des Affaires Sanitaires et Sociales) and Dr Shirley Ballivet-Gervolino for their contribution to the study. They are grateful to Michèle Reynier for her help during data collection in New Caledonia. 
References

Akslen LA, Haldorsen T, Thoresen SO, Glattre E (1993). Incidence pattern of thyroid cancer in Norway: influence of birth cohort and time period. International Journal of Cancer 53: 183-187.

Bacher-Stier C, Riccabona G, Totsch M, Kemmler G, Oberaigner W, Moncayo R (1997). Incidence and clinical characteristics of thyroid carcinoma after iodine prophylaxis in an endemic goiter country. Thyroid 7: 733-741.

Ballivet S, Salmi LR, Dubourdieu D (2000). Capture-recapture method to determine the best design of a surveillance system. Application to a thyroid cancer registry. Eur J Epidemiol 16: 147-153.

Ballivet S, Salmi LR, Dubourdieu D, Bach F (1995). Incidence of thyroid cancer in New Caledonia, South Pacific, during 1985-1992. American Journal of Epidemiology 141: 741-746.

Baumann F, Rougier Y (2005). Registre du cancer de Nouvelle-Calédonie, bilan de 15 années de surveillance, 1989-2003. Bulletin épidémiologique hebdomadaire 34: 169-171.

Besag JE, York JC, Mollié A (1991). Bayesian image restoration with two applications in spatial statistics. Annals of the Institute of Statistical Mathematics 43: 1-59.

Breslow NE , Day NE (1987). Statistical methods in cancer research. Volume 2 - The design and analysis of cohort studies. IARC Scientific Publications, Lyon.

Burgess JR (2002). Temporal trends for thyroid carcinoma in Australia: an increasing incidence of papillary thyroid carcinoma (1982-1997). Thyroid 12: 141-149.

Colonna M, Grosclaude P, Remontet L, Schvartz C, Mace-Lesech J, Velten M, Guizard A, Tretarre B, Buemi AV, Arveux P, Esteve J (2002). Incidence of thyroid cancer in adults recorded by French cancer registries (1978-1997). European Journal of Cancer 38: 1762-1768.

dos Santos Silva I, Swerdlow AJ (1993). Thyroid cancer epidemiology in England and Wales: time trends and geographical distribution. British Journal of Cancer 67: 330-340.

Ferlay J, Bray F, Pisani P, Parkin DM (2004). GLOBOCAN 2002 - Cancer Incidence, Mortality and Prevalence Worldwide - IARC Cancer Base No. 5, version 2.0. IARC Press, Lyon, 2004.

Franceschi S, La Vecchia C, Bidoli E (1998). High incidence of thyroid cancer in central Italy [letter]. Int J Cancer 77: 481-482.

Gaitan E (1990). Goitrogens in food and water. Annu Rev Nutr 10: 21-39.

Gharib H, Goellner JR (1993). Fine-needle aspiration biopsy of the thyroid: an appraisal. Ann Intern Med 118: 282-289.

Goodman MT, Yoshizawa CN, Kolonel LN (1988). Descriptive epidemiology of thyroid cancer in Hawaii. Cancer 61: 1272-1281.

Hedinger C, Williams ED, Sobin LH (1988). Histological typing of thyroid tumours. SpringerVerlag, New York - Berlin - Heidelberg.

Hodgson NC, Button J, Solorzano CC (2004). Thyroid cancer: is the incidence still increasing? Ann Surg Oncol 11: 1093-1097.

Hrafnkelsson J, Jonasson JG, Sigurdsson G, Sigvaldason H, Tulinius H (1988). Thyroid cancer in Iceland 1955-1984. Acta Endocrinol (Copenh) 118: 566-572. 
International Classification of Diseases for Oncology, Second Edition (1990). World Health Organization, Geneva

ITSEE-INSEE (1997). Recensement de la population de Nouvelle-Calédonie, principaux tableaux 1996. ITSEE-INSEE, Nouméa.

Leenhardt L, Bernier MO, Boin-Pineau MH, Conte DB, Marechaud R, Niccoli-Sire P, Nocaudie M, Orgiazzi J, Schlumberger M, Wemeau JL, Cherie-Challine L, De VF (2004a). Advances in diagnostic practices affect thyroid cancer incidence in France. Eur J Endocrinol 150: 133-139.

Leenhardt L, Grosclaude P, Cherie-Challine L (2004b). Increased incidence of thyroid carcinoma in france: a true epidemic or thyroid nodule management effects? Report from the French Thyroid Cancer Committee. Thyroid 14: 1056-1060.

Liu S, Semenciw R, Ugnat AM, Mao Y (2001). Increasing thyroid cancer incidence in Canada, 1970-1996: time trends and age-period-cohort effects. British Journal of Cancer 85: 1335-1339.

Mahoney MC, Lawvere S, Falkner KL, Averkin YI, Ostapenko VA, Michalek AM, Moysich KB, McCarthy PL (2004). Thyroid cancer incidence trends in Belarus: examining the impact of Chernobyl. International Journal of Epidemiology 33: 1025-1033.

Marqusee E, Benson CB, Frates MC, Doubilet PM, Larsen PR, Cibas ES, Mandel SJ (2000). Usefulness of ultrasonography in the management of nodular thyroid disease. Ann Intern Med 133: 696-700.

Paksoy N (1988). Frequency of thyroid cancer in Pacific populations. Journal of the National Cancer Institute 61: 1272-1281.

Pottier D (1992). Population at risk. In: Cancer Incidence in Five Continents, Vol VI (eds Parkin D.M., Muir C.S., Whelan S.L., Gao Y.T., Ferlay J., Powell J.) IARC, Lyon, pp. 174-177.

Reynolds RM, Weir J, Stockton DL, Brewster DH, Sandeep TC, Strachan MW (2005). Changing trends in incidence and mortality of thyroid cancer in Scotland. Clin Endocrinol (Oxf) 62: 156162.

Robertson C, Boyle P (1998). Age-period-cohort models of chronic disease rates. II: Graphical approaches. Stat Med 17: 1325-1339.

Spielgelhalter DJ, Thomas A, Best NG (2001). WinBUGS Version 1.4, User Manual. In: Medical Research Council Biostatistics Unit Cambridge, and Imperial College School of Medicine, London, UK.

Spitz M, Sider JG, Katz RL, Pollack ES, Newell GR (1988). Ethnic patterns of thyroid cancer incidence in th United States, 1973-1981. International Journal of Cancer 42: 549-553.

Stewart BW , Kleihues P (2003). World Cancer Report. IARC Press, Lyon.

Truong T, Orsi L, Dubourdieu D, Rougier Y, Hemon D, Guenel P (2005). Role of goiter and of menstrual and reproductive factors in thyroid cancer: a population-based case-control study in New Caledonia (South Pacific), a very high incidence area. American Journal of Epidemiology 161: 1056-1065.

Verkooijen HM, Fioretta G, Pache JC, Franceschi S, Raymond L, Schubert H, Bouchardy C (2003). Diagnostic changes as a reason for the increase in papillary thyroid cancer incidence in Geneva, Switzerland. Cancer Causes and Control 14: 13-17.

Wakefield JC, Best NG, Wallgren A (2000). Bayesian approaches to disease mapping. In: Spatial epidemiology, methods and applications (eds Elliot P., Wakefield J.C., Best N.G., Briggs D.J.) Oxford University Press, Oxford, pp. 104-127. 
Zheng T, Holford TR, Chen Y, Ma JZ, Flannery J, Liu W, Russi M, Boyle P (1996). Time trend and age-period-cohort effect on incidence of thyroid cancer in Connecticut, 1935-1992.

International Journal of Cancer 67: 504-509. 
Figure 1- Age-standardized incidence rates (ASR) of thyroid cancer and 95\% confidence intervals by sex in New Caledonia, 1985-1999.

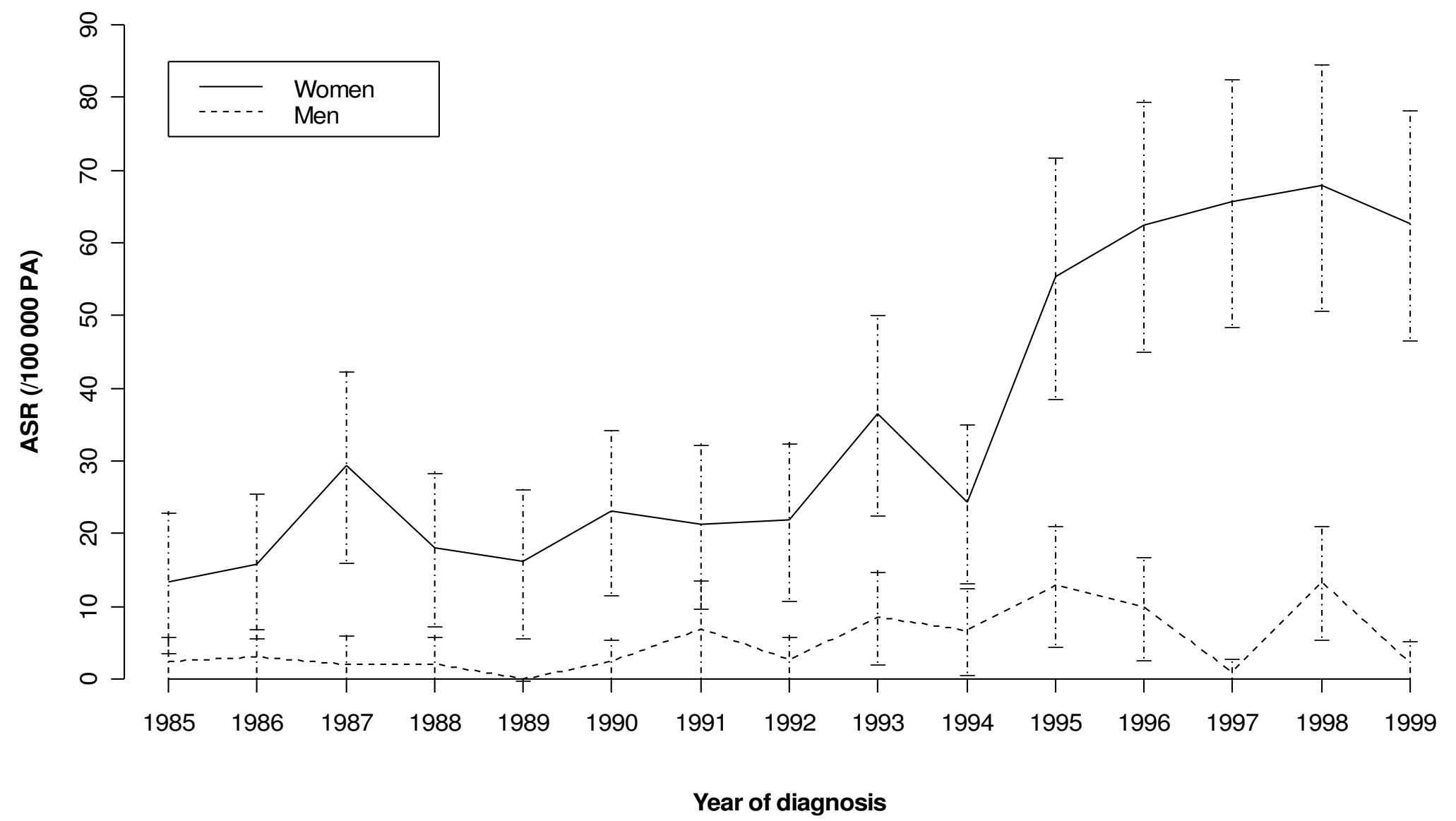


Table 1 - Number of cases and age-standardized incidence rates (per 100,000) of thyroid cancer for men and women by calendar period in New Caledonia, 1985-1999.

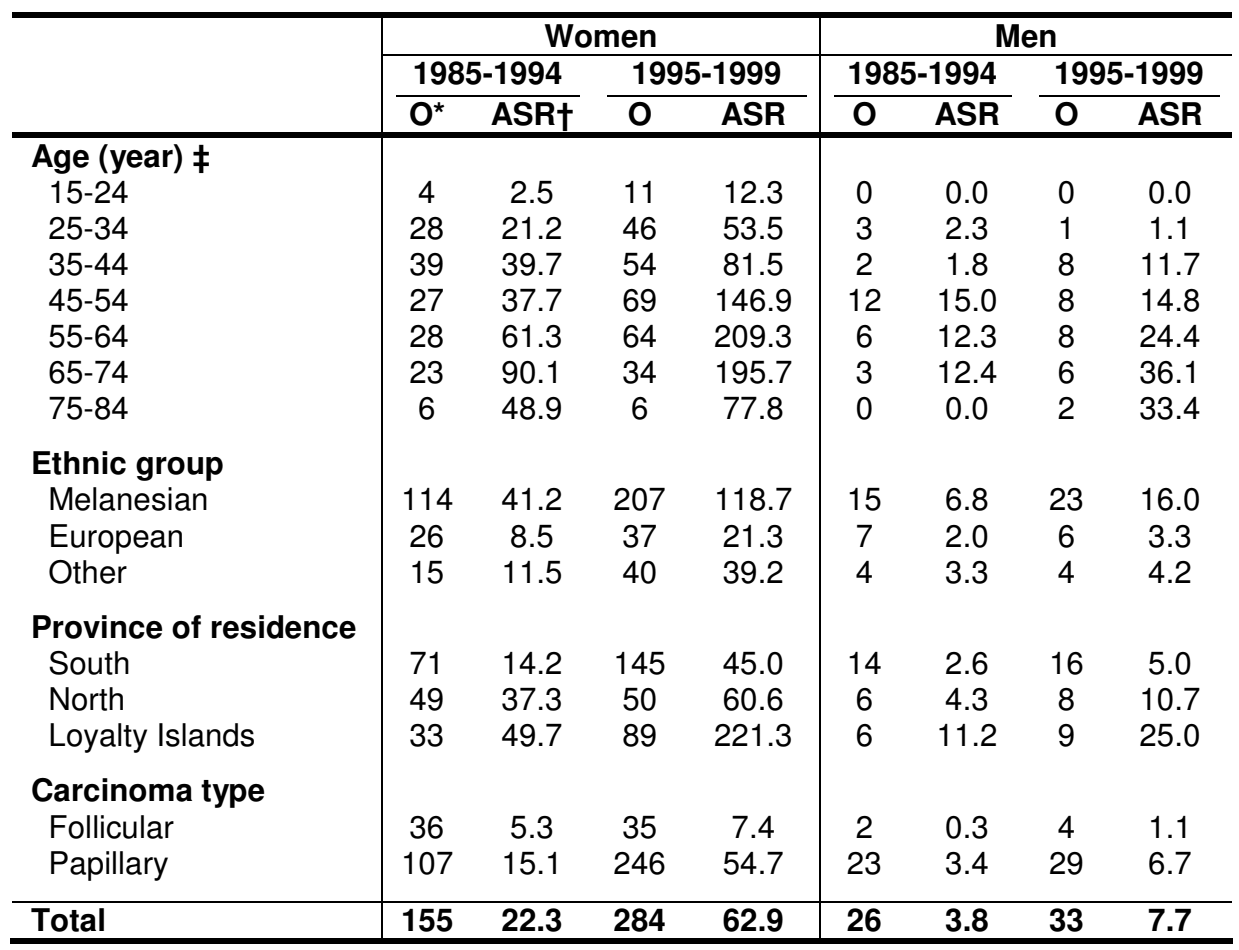

* Observed number of cases

† Age-standardized incidence rates

‡ Incidence rates per age group were not standardized 
Figure 2 - Age-specific incidence rates (in a logarithmic scale) of thyroid cancer in women by period of diagnosis (figure 2a) and by birth cohort (figure 2b) in New Caledonia, 1985-1999.

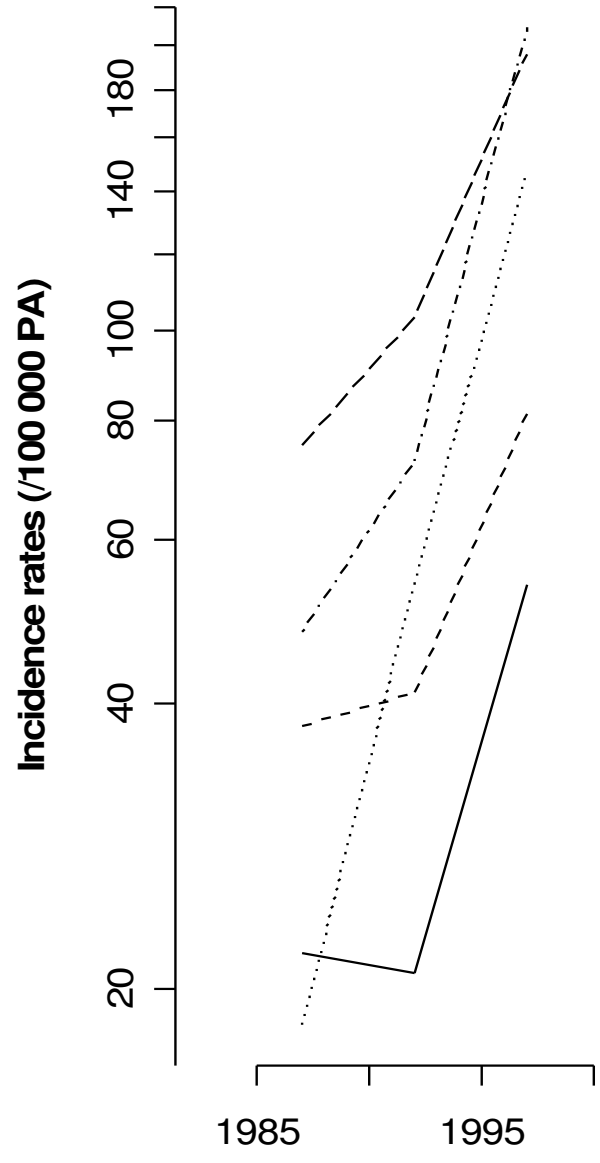

Period of diagnosis

Figure 2a

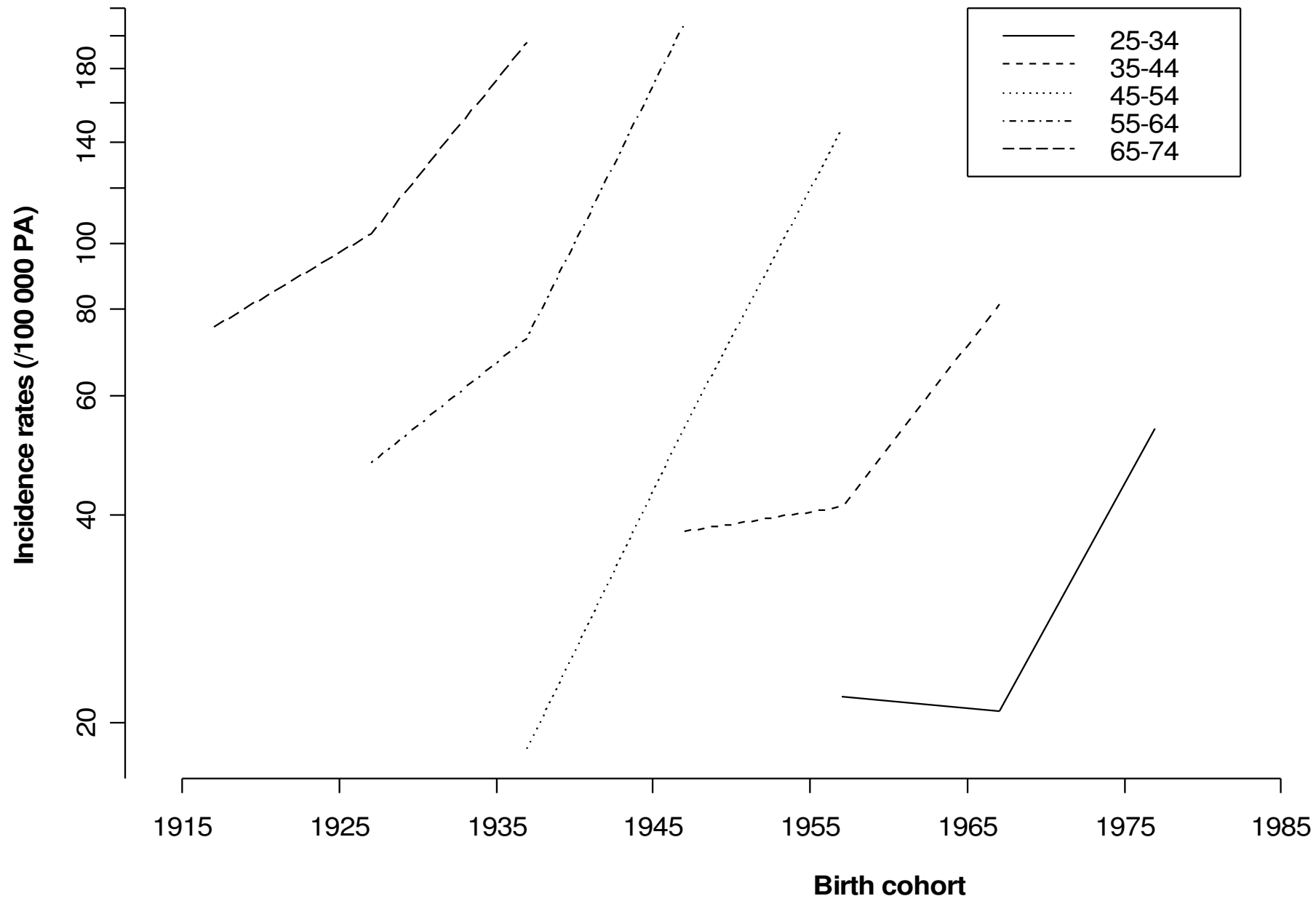

Figure 2b 
Table 2 - Number of cases of papillary thyroid cancer and age standardized incidence rates per 100,000 , per ethnic group, period and size of carcinoma in women of New Caledonia, 19931999.

\begin{tabular}{|c|c|c|c|c|c|c|c|}
\hline \multirow{3}{*}{ Ethnicity } & \multirow{3}{*}{ Period } & \multicolumn{6}{|c|}{ Size of carcinoma } \\
\hline & & \multicolumn{3}{|c|}{$\leq 10 \mathrm{~mm}$} & \multicolumn{3}{|c|}{$>10 \mathrm{~mm}$} \\
\hline & & $\mathbf{O}^{*}$ & ASR† & SD\# & 0 & ASR & SD \\
\hline \multirow[t]{3}{*}{ Melanesian } & 1993-1994 & 7 & 11.6 & 4.5 & 18 & 29.4 & 7.1 \\
\hline & 1995-1997 & 45 & 45.2 & 6.9 & 53 & 51.4 & 7.3 \\
\hline & 1998-1999 & 50 & 71.0 & 10.2 & 29 & 38.4 & 7.4 \\
\hline \multirow[t]{3}{*}{ European } & 1993-1994 & 4 & 6.3 & 3.2 & 2 & 2.4 & 1.7 \\
\hline & 1995-1997 & 16 & 16.3 & 4.2 & 6 & 5.6 & 2.3 \\
\hline & 1998-1999 & 4 & 5.1 & 2.7 & 7 & 9.0 & 3.4 \\
\hline \multirow[t]{3}{*}{ Other } & 1993-1994 & 3 & 8.0 & 4.7 & 3 & 9.0 & 5.2 \\
\hline & $1995-1997$ & 10 & 15.8 & 5.1 & 7 & 12.6 & 5.0 \\
\hline & 1998-1999 & 8 & 17.8 & 6.5 & 10 & 23.1 & 7.5 \\
\hline \multirow[t]{3}{*}{ All } & 1993-1994 & 14 & 8.9 & 2.4 & 23 & 14.6 & 3.1 \\
\hline & $1995-1997$ & 71 & 27.8 & 3.4 & 66 & 25.3 & 3.2 \\
\hline & 1998-1999 & 62 & 32.5 & 4.2 & 46 & 23.4 & 3.5 \\
\hline Total & 1993-1999 & 147 & 24.5 & 2.1 & 135 & 22.0 & 1.9 \\
\hline
\end{tabular}

* Observed number of cases

$\dagger$ Age-standardized incidence rate $\$$ Standard deviation 
Table 3 - Number of cases of papillary thyroid cancer and age standardized incidence rates per 100,000 , per province, period and size of carcinoma in Melanesian women of New Caledonia, 1993-1999.

\begin{tabular}{|c|c|c|c|c|c|c|c|}
\hline \multirow{3}{*}{ Province } & \multirow{3}{*}{ Period } & \multicolumn{6}{|c|}{ Size of carcinoma } \\
\hline & & \multicolumn{3}{|c|}{$\leq 10 \mathrm{~mm}$} & \multicolumn{3}{|c|}{$>10 \mathrm{~mm}$} \\
\hline & & $\mathbf{O}^{*}$ & ASRt & SD‡. & 0 & ASR & SD \\
\hline South & $\begin{array}{l}1993-1994 \\
1995-1997 \\
1998-1999\end{array}$ & $\begin{array}{c}2 \\
22 \\
14\end{array}$ & $\begin{array}{c}9.1 \\
53.2 \\
49.9\end{array}$ & $\begin{array}{c}6.9 \\
11.9 \\
13.8\end{array}$ & $\begin{array}{c}2 \\
15 \\
12\end{array}$ & $\begin{array}{c}5.9 \\
43.3 \\
41.3\end{array}$ & $\begin{array}{l}4.2 \\
11.7 \\
12.3\end{array}$ \\
\hline North & $\begin{array}{l}1993-1994 \\
1995-1997 \\
1998-1999\end{array}$ & $\begin{array}{c}2 \\
6 \\
18\end{array}$ & $\begin{array}{c}8.1 \\
16.9 \\
77.0\end{array}$ & $\begin{array}{c}5.9 \\
7.0 \\
18.4\end{array}$ & $\begin{array}{c}13 \\
10 \\
6\end{array}$ & $\begin{array}{l}60.1 \\
25.7 \\
16.6\end{array}$ & $\begin{array}{l}17.0 \\
8.4 \\
6.8\end{array}$ \\
\hline Loyalty Islands & $\begin{array}{l}1993-1994 \\
1995-1997 \\
1998-1999\end{array}$ & $\begin{array}{c}3 \\
17 \\
18\end{array}$ & $\begin{array}{c}24.4 \\
77.3 \\
113.6\end{array}$ & $\begin{array}{l}14.1 \\
19.1 \\
27.4\end{array}$ & $\begin{array}{c}3 \\
28 \\
11\end{array}$ & $\begin{array}{c}20.6 \\
120.7 \\
70.9\end{array}$ & $\begin{array}{l}11.9 \\
23.4 \\
21.9\end{array}$ \\
\hline Total & 1993-1999 & 102 & 44.6 & 4.5 & 100 & 41.7 & 4.3 \\
\hline
\end{tabular}

* Observed number of cases

$\dagger$ Age-standardized incidence rate $\$$ Standard deviation 
Figure 3-Standardized incidence ratios of thyroid cancer for Melanesian women by municipality of residence in New Caledonia. Figure 3a: calendar period 1985-1994. Figure 3b: calendar period 1995-1999. Expected numbers of thyroid cancer were calculated using incidence rates for all Melanesian women in the corresponding period.

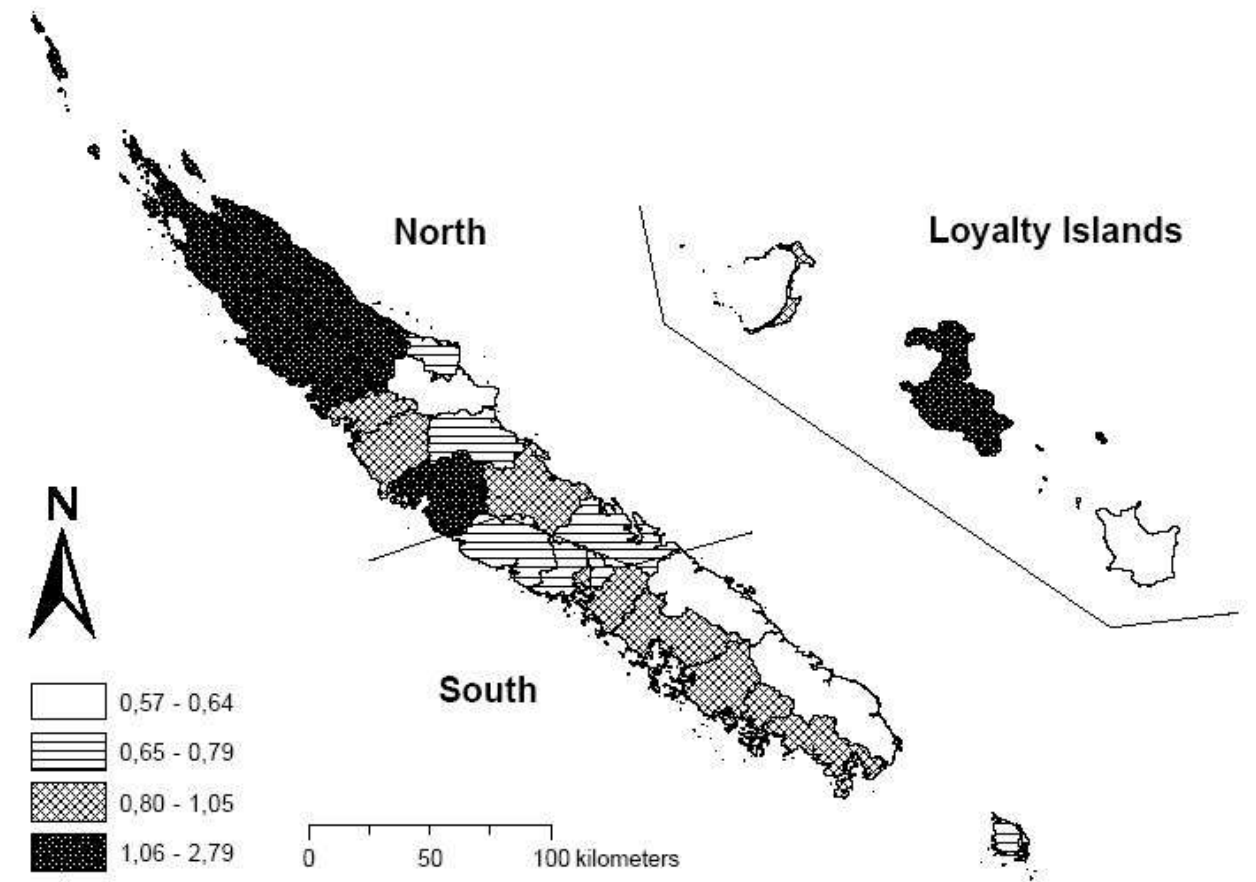

Figure 3a-1985-1994

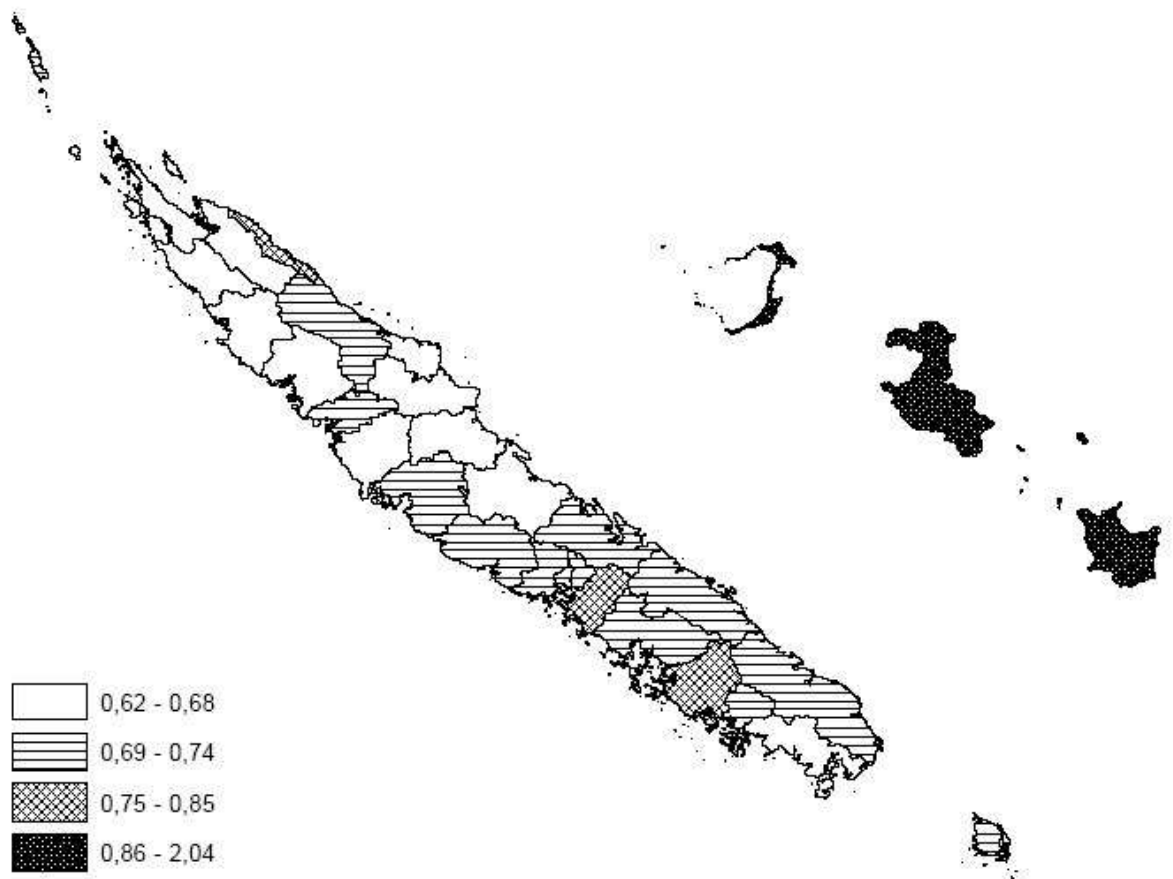

Figure 3b - 1995-1999 